\title{
Hepatitis C Virus Infection: Molecular Pathways to Insulin resistance
}

\author{
Fahed Parvaiz ${ }^{\dagger}$, Sobia Manzoor ${ }^{\dagger}$, Huma Tariq, Farakh Javed, Kaneez Fatima and Ishtiaq Qadri ${ }^{*}$
}

\begin{abstract}
Chronic Hepatitis $C$ virus has the potential of inducing insulin resistance and type 2 Diabetes Mellitus in vitro as well as in vivo. Structural and non-structural proteins of HCV modulate cellular gene expression in such a way that insulin signaling is hampered, concomitantly leads toward diabetes mellitus. A number of mechanisms have been proposed in regard to the HCV induced insulin resistance involving the upregulation of Inflammatory cytokine TNF$\alpha$, hypophosphorylation of IRS-1 and IRS-2, phosphorylation of Akt, up-regulation of gluconeogenic genes, accumulation of lipids and targeting lipid storage organelles. This review provides an insight of molecular mechanisms by which HCV structural and non-structural proteins can induce insulin resistance.
\end{abstract}

Keywords: HCV Infection, Molecular Pathways, Insulin Resistance

\section{Background}

$\mathrm{HCV}$, a blood born pathogen, belongs to the family Flavivridae, infects hepatocytes and was discovered in 1989. The genome size of $\mathrm{HCV}$ is $9.6 \mathrm{~Kb}$ that encodes about 3010 amino acids and gets translated into structural and nonstructural proteins [1-3].

$\mathrm{HCV}$ is a major cause of acute and chronic liver disease worldwide [4-6]. Acute HCV infection becomes persistent in about $85 \%$ of cases [7]. Chronic infection with HCV is a multifaceted disorder associated with insulin resistance, glomerulonephritis, B-cell lymphoma and type 2 diabetes mellitus [8]. It is estimated that $3.3 \%$ of the population globally (lower in Europe 1.03\% and highest in Africa $5.3 \%$ ) and $10 \%$ of the Pakistani population is chronically infected with HCV [9-12]. Until now, there is no vaccine against $\mathrm{HCV}$ that can provide effective immunization [13].

The process of glucose uptake is quite complicated that involves binding of insulin to the insulin receptor and subsequently binds to Insulin receptor substrate 1 (IRS-1), activating a number of different kinds of proteins like PIK3, PDC and PIP3 which in turns, activates GLUT4 and causes the translocation of glucose from exoplasmic surface to the inside of cell [14]. After glucose is internalized, glucose gets phosphorylated by hexokinase, enters

\footnotetext{
* Correspondence: ishtiaq80262@yahoo.com

† Contributed equally

NUST Center of Virology and Immunology (NCVI), National University of

Sciences and Technology (NUST), Islamabad 44000, Pakistan
}

glycolysis and gets converted into pyruvate. This glucose is taken up by the adipocytes and is utilized in the formation of lipids while, in case of muscles, glucose is converted into glycogen and glycogenolysis is inhibited by insulin. In liver, insulin downregulates glucose level by inhibiting gluconeogensis and glycogenolysis involving Phosphoenolpyruvate carboxy kinase (PEPCK), key regulator of gluconeogensis $[15,16]$.

Any change in this signaling is likely to induce insulin resistance which is associated with a number of pathophysiological changes including glucose intolerance, obesity, dyslipidemia and hypertension. During the course of insulin resistance several inflammatory cytokines and lipid metabolites like free fatty acids interrupt with the normal insulin signaling and promote type 2 diabetes mellitus [14].

\section{HCV Induced Insulin resistance}

Insulin resistance is a pre-diabetic phase that is frequently observed in chronic HCV patients (25\%) and lesser in case of other hepatic disorders including hepatitis B virus (10\%) [17]. Non-alcoholic fatty liver disease (NAFLD) is one of the most important causes of chronic infections and Insulin resistance (IR) represents the hallmark of NAFLD. It is a systemic disorder that not only infects liver but also nervous system, pancreas, heart, kidney and muscles [18]. IR is a condition where adequate amount of insulin is required to maintain the 
glucose level or normal insulin concentration is unable to maintain homeostasis $[19,20]$. Glucose intolerance is related to diminish sustained virological response that promotes insulin resistance, a step leading towards steatosis and hepatocellular carcinoma [21,22]. Although the characteristics and complications of $\mathrm{HCV}$ are well identified, but the molecular mechanisms of $\mathrm{HCV}$ induced IR and hepatocellular carcinoma are yet to be fully understood [23,24].

Hepatitis $\mathrm{C}$ virus infects the hepatocytes, progresses through chronic phase and eventually leads towards IR, Type 2 Diabetes mellitus and Steatosis. The prevalence of Type 2 diabetes mellitus in chronic HCV patient ranges from $24-50 \%$ and this frequency is about 5 times greater than the rest of Hepatic cirrhosis [25,26].

Several studies revealed that HCV infection promotes the release of tumor necrosis factor alpha (TNF- $\alpha$ ). These metabolic disorders like IR and steatosis are dependent on the sustained virological response (SVR) i. e. reduction of IR and steatosis will be favored in response to the high SVR [27].

\section{Role of HCV structural and non-structural proteins in Insulin Resistance}

The genome size of HCV is about $9.6 \mathrm{~kb}$ which gets translated into 10 different structural and non structural proteins. These proteins help virus to replicate and damage host machinery. However HCV proteins Core, NS-3 and NS-5 are mainly involved in IR. The core protein is involved in the formation of capsid, NS-3 contains helicase and proteolytic activity, NS-5A downregulates interferon stimulated genes and NS-5B is a RNA polymerase $[28,29]$. The structural organization of $\mathrm{HCV}$ genome is given the figure. A brief role of HCV structural and non-structural proteins in the induction of insulin resistance is discussed here (Figure 1).

\section{Core Protein}

$\mathrm{HCV}$ Core protein is a pathogenic feature of this virus that can induce several metabolic disorders in the host cell. HCV induces insulin resistance by knocking out PPAR $28 \square$ by the way of core protein induction. PPAR 28-/- core Ag leads to the hypophosphorylation of Insulin receptor substrate (IRS)-1 as well as 2 and phosphorylation of Akt [30]. Another study has showed similar results in which HCV core transgenic Huh 7 and HepG2 cells expressed low levels of IRS-1 and IRS-2 with the concomitant increased expression of SOCS-3 [31]. HCV Core transgenic mice were shown to block P85 subunit of PI3K, a downstream insulin signaling molecule, and impair insulin signaling pathways [32].

TNF- $\alpha$, antioxidant gene, is found to be released in an excess and is required for the phosphorylation of serine residues of IRS-1 eventually leading to the downregulation of downstream insulin signaling molecule Akt. HCV core protein increases the expression level of TNF- $\alpha$ and promotes insulin resistance [33]. In response to this oxidative stress, four major DNA glycosylases are unregulated i.e. NTH1, OGG1, NEIL1 and NEIL2. HCV Structural as well as Non-Structural proteins interferes with these glycosylases. Expression of NEIL1 is strongly down regulated by Core protein and to a lesser extent by NS-3, NS-4A and NS-5A [34].

\section{NS-3 Protein}

HCV Non structural protein 3 (NS-3) has been shown to induce oxidative stress by the way of reactive oxygen species (ROS). During viral replication, NS-3 induces the upregulation of Nicotinamide adenine dinucleotide phosphate oxidase 2 (NOX2) which, in turns, accelerates the production of ROS eventually leading to the modulation in downstream signaling pathways like hepatic fibrosis [35]. It has been found that NS-3 cans downregulate Tcells and natural killer cells thereby promoting its proteolytic activity [36]. Secondary structure of NS-3 has the potential of inducing neoplastic transformation and can lead towards carcinoma [37]. Yet its direct role in the induction of insulin resistance has not been determined.

\section{NS-5A Protein}

NS5A potentially interacts with RNA dependant kinase (PKR), linked to the IFN stimulated genes, downregulates PKR and consequently diminishes the IFN response against HCV RNA [28]. There is correlation between the interferon responsiveness and the phosphorylation of eIF-2 $\alpha$. NS5A expression masks the effect of PKR which, in turns, lowers the phosphorylation of eIF- $2 \alpha$ and promotes interferon resistance [38].

HCV Non Structural protein 5A (NS-5A) co-localizes on the ER membrane, promotes lipid accumulation and reactive oxygen species (ROS) that modulate intracellular signaling involving transcriptional factors like NF-kB, STAT3 and $\mathrm{Ca}^{2+}$ ions and promote damage to the hepatocytes [39]. By this way of damage to the hepatocytes, NS5A induces ER stress which leads to insulin resistance directly or indirectly by the upregulation of cellular gene protein phosphatase 2A (PP2A) [40,41]. PP2A has been shown to downregulate Akt, which in turns, hampers the insulin signaling as well as it induces interferon resistance. Therefore, NS5A plays a pivotal role in the developing interferon resistance and takes its path towards IR $[42,43]$.

Studies on transgenic mice expressing NS-5A reveals that this protein interacts with Apolipoprotein-1 of the fatty hepatocytes, hampers the lipid transport, accumulates cholesteryl esters and thereby leads towards liver pathology including Steatosis and hepatocellular carcinoma [44]. 

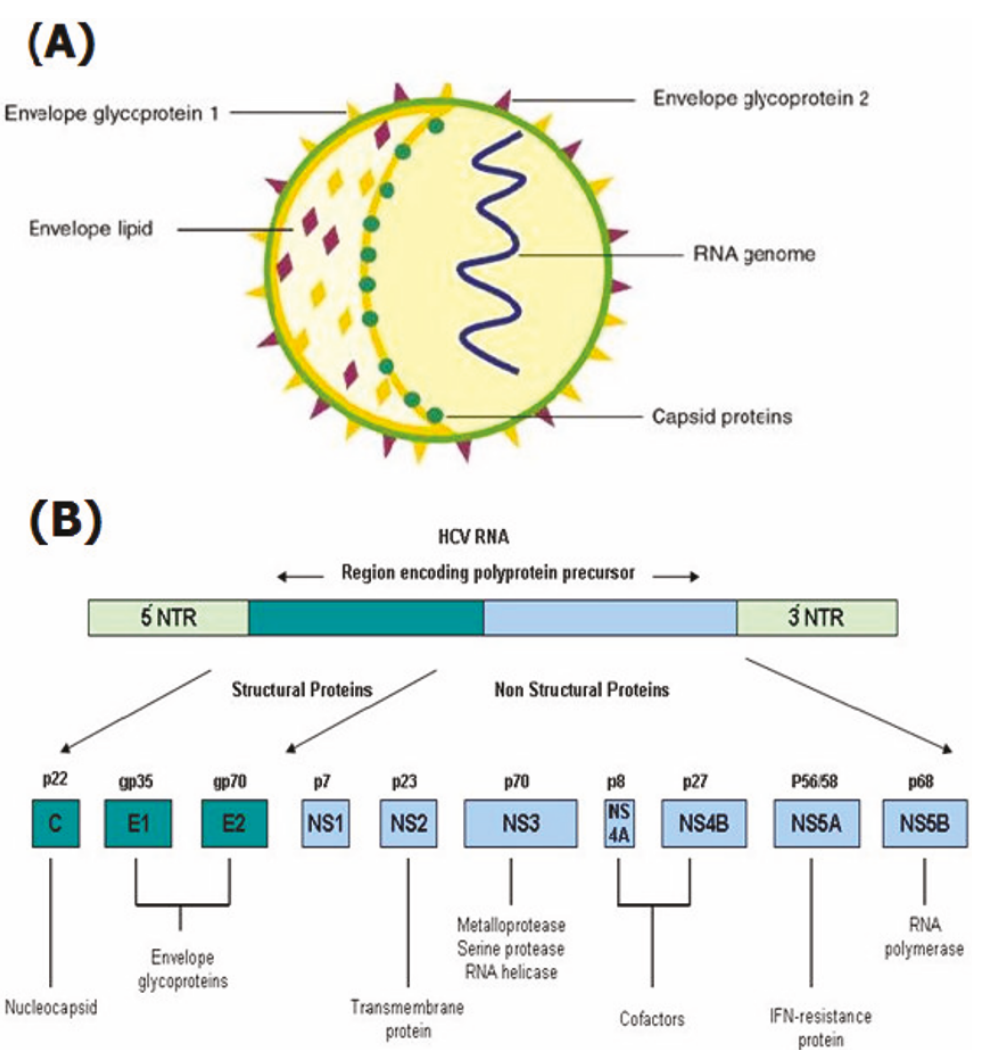

Figure 1 Model Structure of HCV: Section A: Generalized structure of Hepatitis C virus, Section B: Genomic organization of HCV that gets translated into three structural and seven non-structural proteins

HCV NS-5A has great potential of interacting with ER and inducing stress on the ER homeostasis by the way of upregulating ER over load Response (EOR). During this phenomenon, one of the key transcriptional factors of untranslated protein response ATF6 is upregulated. However, the exact mechanism by which NS5A is inducing the EOR is still remaining unknown [38]. This Figure illustrates the sequential pathways involving $\mathrm{HCV}$ induced insulin resistance (Figure 2).

\section{Role of cellular factors contributing in HCV Induced Insulin Resistance}

Some of the cellular factors which are found to be involved in promoting insulin resistance are explained here.

\section{Role of cytokines}

Various HCV proteins interact with the endoplasmic reticulum and mitochondria induces oxidative stress with the concomitant upregulation of TNF- $\alpha$ and some other cytokines like Interleukin8, Interleukin6, Tumor growth factor- $\beta$ and Fas ligand [45]. As TNF- $\alpha$ is critically important for the determination of $\mathrm{HCV}$ infection. TNF- $\alpha$ is an inflammatory cytokine that is strongly upregulated in $\mathrm{HCV}$ infection and downregulates the insulin signaling mechanisms by blocking the phosphorylation of key molecules Insulin receptor Substrates (IRS) and hampers the GLUT4 translocation for the glucose molecule across the plasma membrane of the host cell. [46].

\section{Role of IRS}

Depending upon the genotype, HCV induced Insulin resistance can be promoted by a number of mechanisms like Genotype 1 can deteriorate IRS-1 by the ubiquitinylation favored by SOCS-3. In case of genotype $1 \mathrm{~b}$, IRS- 1 is down regulated by mTOR (mammalian target of Rapamycin) that causes the serine/threonine phosphorylation of IRS-1 and hampers normal insulin signaling. In genotype 3, there is enhanced production of SOCS7 that diminishes IRS-1 and promotes insulin resistance [47-49].

\section{Role of Akt}

Akt, the downstream insulin signaling molecule, effectively governs the transport of glucose through a controlled feedback mechanism involving PKC and protein tyrosine phosphatase $1 \mathrm{~B}$ (PTP1B). Insulin signaling is favored by doing the phosphorylation of PTP-1B. As a 


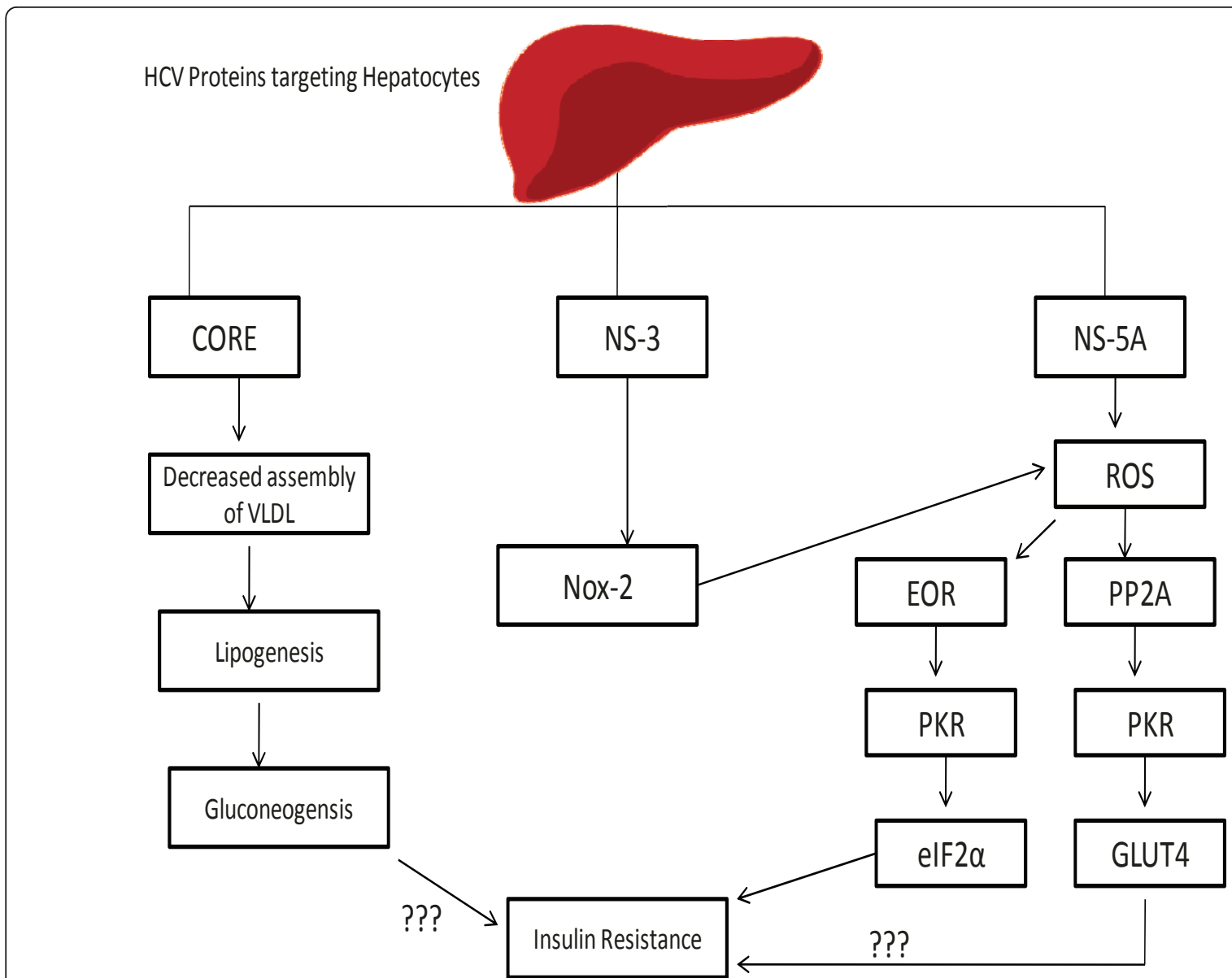

Figure 2 Schematic Representation of HCV Induced Insulin Resistance: Figure demonstrates that HCV non-structural proteins (NS-3 and NS$5 \mathrm{~A})$ and structural protein (Core Protein) modulate various cellular genes that are involved in insulin resistance.

negative feedback mechanism, PKC can phosphorylate the serine residues of IRS-1 thereby blocking the IRS-1/ PI3K complex and inhibit insulin signaling [50]. IRS can activate a number of insulin linked proteins like $\mathrm{Src} 2$ homology domain containing proteins, Fyn, CSK, CRK, NCK as well as Akt. However, Akt is given more importance because of its strong role in insulin signaling. As far as IRS dependant Akt mediated signaling is concerned, it activates PDK which, in turns, phophorylates and activates two proteins Akt (also known as PKB) and PKC with the dominant isoforms zeta and lambda. Although Akt predominates in this pathway, still a number of other cellular factors have to be explored that are crucially involved in this pathway [51]. Recent evidence shows that Huh 8 cells expressing HCV NS-5A induced IR by the way of downregulating serine-473residue of Akt and Insulin receptor- $\beta$ [52].

\section{Role of lipogenic genes}

Previously it was thought that insulin resistance is just because of the excessive glucose or imbalanced glucose metabolism. However, it is now revealed that insulin resistance is strongly influenced by abnormalities in the lipid metabolism. Any dysfunction of the leptin triggers lipotoxicity through the production of free fatty acids in skeletal muscles, myocardium and pancreatic islets thereby promoting insulin resistance [53]. After the HCV infection, core protein down-regulates microsomal triglyceride transfer protein (MTP), an enzyme that mediates lipids translocation to the ER membrane and decreases the assembly of very low density lipoproteins (VLDL) [54]. Consequently, there is an enhanced production of lipids that promotes insulin dependent steatosis in a MAP kinase pathway [55]. AMP-activated protein kinase (AMPK) is involved in controlling lipid as well as glucose metabolism. During the HCV replication, AMPK is phosphorylated at threonine 172, promoting lipid accumulation thereby favoring HCV induced insulin resistance [56].

\section{Role of gluconeogenic genes}

$\mathrm{HCV}$ infection promotes the expression of gluconeogenic genes which, in turns, enhances insulin resistance. 
It has been observed that $\mathrm{HCV}$ promotes fatty acid synthesis by the upregulation of lipogenic gene sterol regulatory element binding protein $1 \mathrm{c}$ which promotes the transcriptional activation of other lipogenic genes like acetyl CoA carboxylase, ATP citrate lyase, hydroxymethylglutaryl CoA reductase etc [57].

Findings of a recent study have revealed that in $\mathrm{HCV}$ infected cell line Huh.8, PEPCK which is a key regulator of gluconeogenesis, as well as cellular lipids was strongly upregulated under HCV NS-5A expression. This is indicating a plausible role of NS-5A in gluconeogenesis and imbalances in the glucose metabolism [45].

\section{Conclusion}

$\mathrm{HCV}$ is a multifaceted disorder that involves different cellular and viral factors for the disease progression. Chronic $\mathrm{HCV}$ infection is more likely to favor IR by the way of $\mathrm{HCV}$ core, NS-3 and NS-5A protein. These proteins are under strict investigation because there analogues can prove to be effective treatment against $\mathrm{HCV}$ infection. We can conclude that HCV induced IR is not merely because of glucose imbalances rather it involves upregulation of the gluconeogenic and lipogenic genes that promote glucose intolerance and progresses towards IR, a step towards hepatocellular carcinoma.

\section{Abbreviations \\ HCV: Hepatitis C virus; IRS: insulin receptor substrate; GLUT: glucose transporter; PEPCK: phosphoenol pyruvate carboxykinase; NAFLD: non- alcoholic fatty liver disease; IR: insulin resistance; TNF-a: tumor necrosis factor alpha; SVR: sustained virological response; NS: non-structural proteins; ROS: reactive oxygen species; NOX2: nicotinamide adenine dinucleotide phosphate oxidase 2; PKR: protein kinase R; elF: eukaryotic initiation factor; ER: endoplasmic reticulum; STAT: signal transducer and activator of transcription; PP2A: protein phosphatase 2A; ATF: activated transcription factor; MAP: mitogen activated pathway, AMPK: AMP-activated protein kinase}

\section{Acknowledgements}

Financial support in part by Higher Education Commission (grant 829), USPakistan grant between Dr. Ishtiaq Qadri and Dr. Charles M. Rice, Rockefeller University, New York, NY, USA) is highly acknowledged.

\section{Authors' contributions}

FP and SM reviewed the literature, and wrote the manuscript. IQ edited the manuscript. HT, FJ and KF helped FP and SM in literature review. All the authors read and approved the final manuscript.

\section{Competing interests}

The authors declare that they have no competing interests.

Received: 3 June 2011 Accepted: 18 October 2011

Published: 18 October 2011

\section{References}

1. Choo QL, Kuo G, Weiner AJ, Overby LR, Bradley DW, Houghton M: Isolation of a cDNA clone derived from a blood-borne non- $A$, non- $B$ viral hepatitis genome. Science 1989, 244:359-362.

2. Bartenschlager $R$, Kaul A, Sparacio $S$ : Replication of the hepatitis $C$ virus in cell culture. Antiviral Res 2003, 60:91-102.

3. Bartenschlager R, Lohmann V: Replication of hepatitis C virus. J Gen Virol 2000, 81:1631-1648.
4. Miura K, Taura K, Kodama Y, Schnabl B, Brenner DA: Hepatitis C virusinducedoxidative stress suppresses hepcidin expression through increased histone deacetylase activity. Viral Hepatitis 2008, 48(5):1420-1429.

5. Joyce MA, Walters KA, Lamb SE, Yeh MM, Zhu LF, Kneteman N, Doyle JS, Katze MG, Tyrrell DL: HCV Induces Oxidative and ER Stress, and Sensitizes Infected Cells to Apoptosis in SCID/Alb-uPA Mice. PLoS Pathog 2009, 5(2): e1000291.

6. Clement S, Pascarella S, Negro F: Hepatitis C Virus Infection: Molecular Pathways to steatosis, Insulin resistance and oxidative stress. Virus 2009, 1:126-143.

7. Micallef JM, Kaldor JM, Dore GJ: Spontaneous viral clearance following acute hepatitis $C$ infection: a systematic review of longitudinal studies. J. Viral Hepat 2006, 13(1):34-41.

8. Subhash C, Sanjiv C: Hepatitis C: A Multifaceted Disease Review of Extrahepatic Manifestations. Ann Intern med 1995, 123:615-620.

9. Raza SA, Clifford GM, Franceschi B: Worldwide variation in the relative importance of hepatitis $B$ andhepatitis $C$ viruses in hepatocellular carcinoma: a systemic review. Br. J.Cancer 2007, 96(7):1127-1134.

10. Farhana M, Hussain I, Haroon TS: Hepatitis C: the dermatologic profile. J. Pak.Assoc. Derm 2009, 18:171-181.

11. Idrees $M$, Riazuddin S: A study of best positive predictors for sustained virological response to interferon alpha plus ribavirin therapy in naïve hepatitis C patients. BMC Gast 2009, 9:5.

12. Akbar $\mathrm{H}$, Idrees M, Manzoor S, Rehman IU, Butt S, Yousaf MZ, Rafique $S$, Awan Z, Khubaib B, Akram M, Aftab M: Hepatitis C virus infection: A review of the current and future aspects and concerns in Pakistan. JGMV 2009, 1(2):12-18

13. Hoofnagle $\mathrm{JH}$, Seeff LB: Peginterferon and Ribavirin for Chronic Hepatitis C. New Engl J Med 2006, 355:2444-51.

14. Sesti G: Pathophysiology of insulin resistance. Endocrinology and Metabolism. Best Practice and Research Clinical 2006, 20(4):665-679.

15. Shulman Gl: Cellular mechanisms of insulin resistance. J Clin Invest 2000, 106(2):171-176.

16. Shulman Gl, Rothman DL, Jue T, Stein P, DeFronzo RA, Shulman RG: Quantification of muscle glycogen synthesis in normal subjects and subjects with non-insulin dependent diabetes by $\mathrm{C}$ nuclear magnetic resonance spectroscopy. N Engl J Med 1990, 322(4):223-228.

17. Bugianesi E, McCullough AJ, Marchesini G: Insulin resistance: A metabolic pathway to chronic liver disease. Hepatology 2005, 42:987-1000.

18. Kahn CR: Insulin resistance, insulin insensitivity, and insulin unresponsiveness: a necessary distinction. Metabolism 1978, 27:1893-1902.

19. Campbell PJ, Mandarino LJ, Gerich JE: Quantification of the relative impairment in actions of insulin on hepatic glucose production and peripheral glucose uptake in non-insulin-dependent diabetes mellitus. Metabolism 1988, 37:15-21.

20. Romero-Gomez M, Corpas R, Grande L, Castellano-Megias VM, SanchezMunoz D, del Rocio V, Vazquez-Albertino R: Insulin resistance impairs sustained response rate to antiviral therapy in patients with chronic hepatitis C. Hepatology 2003, 38:747.

21. Hassan MM, Hwang LY, Hatten CJ, Swaim M, Li D, Abbruzzese JL, Beasley P, Patt YZ: Risk factors for hepatocellular carcinoma: synergism of alcohol with viral hepatitis and diabetes mellitus. Hepatology 2002, 36:1206-1213

22. Davila JA, Morgan RO, Shaib Y, McGlynn KA, El-Serag HB: Diabetes increases the risk of hepatocellular carcinoma in the United States: a population based case control study. Gut 2005, 54:533-539.

23. Machado MV, Cortez-Pinto H: Insulin Resistance and steatosis in chronic hepatitis C. Ann. Hepatol 2009, 8(1):S67-S75.

24. Zein CO, Levy C, Basu A, Zein NN: Chronic hepatitis C and type II diabetes mellitus: a prospective cross-sectional study. Am J Gastroenterol 2005, 100:48-55

25. Romero-Gomez M: Insulin resistance and hepatitis C. World J Gastroenterol 2006, 12.7075-7080.

26. Arao M, Murase K, Kusakabe A, Yoshioka K, Fukuzawa Y, Ishikawa T, Tagaya T, Yamanouchi $K$, Ichimiya $H$, Sameshima $Y$ : Prevalence of diabetes mellitus in Japanese patients infected chronically with hepatitis $C$ virus. J Gastroenterol 2003, 38:355-360.

27. Choi J, James JH, Mechanisms of liver injury.III: Oxidative stress in the pathogenesis of hepatitis C virus. Am J Physiol Gastrointest Liver Physiol 2006, 290:G847-G851. 
28. Gale MJ, Blakely SM, Kwieciszewski B, Tan SL, Dossett M, Tang NM, Korth MJ, Polyak SJ, Gretch DR, Katze MG: Mol. Cell. Biol 1998, 18:5208-5218.

29. Miyamoto H, Moriishi K, Moriya K, Murata S, Tanaka K, Suzuki T, Miyamura T, Koike K, Matsuura Y: Involvement of the PA28囚 Dependent Pathway in Insulin Resistance induced by Hepatitis C Virus Core Protein. J Virol 2007, 81(4):1727-1735

30. Kawaguchi T, Yoshida T, Harada M, Hisamoto T, et al: Hepatitis C Virus Down-Regulates Insulin Receptor Substrates 1 and 2 through UpRegulation of Suppressor of Cytokine Signaling 3. Gastrointestinal, Hepatobiliary and Pancreatic Pathol 2004, 165(5):1499-1508.

31. Ade El Satar H, Mahfouz M, Rashed L, Ahmed D: Insulin Resistance in Patients with Chronic Hepatitis C Infection. Aust J Basic Appl sci 2010, 4(10):4554-4558.

32. Banerjee S, Saito K, Ait-Goughoulte M, Meyer K, Ray RB, Ray R: Hepatitis C Virus Core Protein Upregulates Serine Phosphorylation of Insulin Receptor Substrate-1 and Impairs the Downstream Akt/Protein Kinase B Signaling Pathway for Insulin Resistance. J Virol 2008, 82(6):2606-2612.

33. Pal S, Polyak SJ, Bano N, Qiu WC, Carithers RL, Shuhart M, Gretch DR, Das A: Hepatitis $C$ virus induces oxidative stress, DNA damage and modulates the DNA repair enzyme NEIL1. J Gastro Hepatol 2010, 25(3):327-634.

34. Wen F, Brown KE, Britigan BE, Schmidt WN: Hepatitis C core protein inhibits induction of heme oxygenase- 1 and sensitizes hepatocytes to cytotoxicity. Cell Biol Toxicol 2008, 24(2):175-88.

35. Bureau C, Bernad J, Chaouche N, Orfila C, Béraud M, Gonindard C, Alric L, Vinel JP, Pipy B: Nonstructural 3 protein of hepatitis $C$ virus triggers an oxidative burst in human monocytes via activation of NADPH oxidase. $J$ Biol Chem 2001, 276(25):23077-83.

36. Thoren F, Romero A, Lindh M, Dahlgren C, Hellstrand $K$ : A hepatitis C virusencoded, nonstructural protein (NS3) triggers dysfunction and apoptosis in lymphocytes: role of NADPH oxidase-derived oxygen radicals. J Leukoc Biol 2004, 76(6):1180-6.

37. Kasprzak A, Adamek A: Role of hepatitis $C$ virus proteins (C, NS3, NS5A) in hepatic oncogenesis. Hepatol Res 2008, 38(1):1-26

38. Tardif KD, Mori $K$, Siddiqui $A$ : Hepatitis $C$ virus subgenomic replicons induce endoplasmic reticulum stress activating an intracellular signaling pathway. J Virol 2002, 76(15):7453-9.

39. Gong G, Waris G, Tanveer R, Siddiqui A: Human hepatitis C virus NS5A protein alters intracellular calcium levels, induces oxidative stress, and activates STAT-3 and NF-kappa B. Proc Natl Acad Sci 2001, 98(17):9599-604

40. Christen V, Treves S, Duong FH, Heim MH: Activation of endoplasmic reticulum stress response by hepatitis viruses up-regulates protein phosphatase 2A. Hepatol 2007, 46(2):558-65.

41. Georgopoulou U, Tsitoura P, Kalamvoki M, Mavromara P: The protein phosphatase $2 \mathrm{~A}$ represents a novel cellular target for hepatitis $\mathrm{C}$ virus NS5A protein. Biochimie 2006, 88(6):651-62.

42. Bernsmeier $C$, Duong FH, Christen V, Pugnale $P$, Negro F, Terracciano L, Heim $\mathrm{MH}$ : Virus-induced over-expression of protein phosphatase $2 \mathrm{~A}$ inhibits insulin signalling in chronic hepatitis C. J Hepatol 2008 49(3):429-40.

43. Duong FH, Filipowicz M, Tripodi M, La Monica N, Heim MH: Hepatitis C virus inhibits interferon signaling through up-regulation of protein phosphatase 2A. Gastroenterol 2004, 126:263-277.

44. Wang AG, Lee DS, Moon HB, Kim JM, Cho KH, Choi SH, Ha HL, Han YH, Kim DG, Hwang SB, Yu DY: Non-structural 5A protein of hepatitis $C$ virus induces a range of liver pathology in transgenic mice. J Pathol 2009, 219(2):253-62.

45. Sheikh MY, Choi J, Qadri I, Friedman JE, Sanyal AJ: Hepatitis C virus infection: molecular pathways to metabolic syndrome. Hepatol 2008, 47(6):2127-33

46. Hotamisligil GS: The role of TNFalpha and TNF receptors in obesity and insulin resistance. J Intern Med 1999, 245(6):621-5.

47. Pazienza V, Clement S, Pugnale P, Conzelman S, Foti M, Mangia A, Negro F: The hepatitis $C$ virus core protein of genotypes $3 a$ and $1 b$ downregulates insulin receptor substrate 1 through genotype-specific mechanisms. Hepat 2007, 45(5):1164-71

48. Haruta T, Uno T, Kawahara J, Takano A, Egawa K, Sharma PM, Olefsky JM, Kobayashi MA: Rapamycin-sensitive pathway downregulates insulin signaling via phosphorylation and proteasomal degradation of insulin receptor substrate-1. Mol Endocrinol 2000, 14:783-794.
49. Rui L, Yuan M, Frantz D, Shoelson S, White MF: SOCS-1 and SOCS-3 block insulin signaling by ubiquitin-mediated degradation of IRS1 and IRS2. J Biol Chem 2002, 277:42394-42398.

50. Sedaghat AR, Sherman A, Quon MJ: A mathematical model of metabolic insulin signaling pathways. Am J Physiol Endocrinol Metabol 2002, 283(5): E1084-101.

51. Farese RV: Function and dysfunction of a PKC isoforms for glucose transport in insulin-sensitive and insulin-resistant states. Am J Physiol Endocrinol Metab 2002, 283:E1-E11.

52. Choudhury M, Qadri I, Rahman M, Knotts TA, Janssen RC, Iwahashi M, Puljak L, Simon FR, Kilic G, Fitz GJ, Friedman JE: Hepatitis C virus (HCV) associated steatosis and increased gluconeogenic gene expression in Huh8 cells: essential role of NS5A and C/EBPâ. FASEB J 2010, 24(1b):115.

53. Unger $\mathrm{RH}$, Orci L: Lipotoxic diseases of nonadipose tissues in obesity. Intern J Obesity 2000, 24(4):S28-S32.

54. Perlemuter G, Sabile A, Letteron P, Vona G, Topilco A, Chrétien Y, Koike K, Pessayre D, Chapman J, Barba G, Bréchot C: Hepatitis C virus core protein inhibits microsomal triglyceride transfer protein activity and very low density lipoprotein secretion: a model of viral-related steatosis. FASEB J 2002, 16(2):185-94

55. Au WS, Kung HF, Lin MC: Regulation of microsomal triglyceride transfer protein gene by insulin in HepG2 cells: roles of MAPK erk and MAPKp38. Diabetes 2003, 52:1073-1080.

56. Mankouria J, Tedburya PR, Grettona S, Hughesa ME, Griffina SD, Dallas ML, Green KA, D Hardie G, Peers C, Harris M: Enhanced hepatitis C virus genome replication and lipid accumulation mediated by inhibition of AMP-activated protein kinase. PNAS 2010, 107(25):11549-54

57. Kim KH, Hong SP, Kim K, Park MJ, Kim KJ, Cheong J: HCV core protein induces hepatic lipid accumulation by activating SREBP1 and PPAR gamma. Biochem Biophy Res Commun 2007, 355(4):883-8.

doi:10.1186/1743-422X-8-474

Cite this article as: Parvaiz et al:: Hepatitis C Virus Infection: Molecular Pathways to Insulin resistance. Virology Journal 2011 8:474.

\section{Submit your next manuscript to BioMed Central and take full advantage of:}

- Convenient online submission

- Thorough peer review

- No space constraints or color figure charges

- Immediate publication on acceptance

- Inclusion in PubMed, CAS, Scopus and Google Scholar

- Research which is freely available for redistribution

Submit your manuscript at www.biomedcentral.com/submit
C) Biomed Central 